\title{
Morphophonological influences on the comprehension of subject-verb agreement: An ERP study
}

Citation for published version (APA):

Severens, E., Schmitt, B. M., \& Hartsuiker, R. J. (2008). Morphophonological influences on the comprehension of subject-verb agreement: An ERP study. Brain Research, 1228, 135-144. https://doi.org/10.1016/j.brainres.2008.05.092

Document status and date:

Published: 01/01/2008

DOI:

10.1016/j.brainres.2008.05.092

Document Version:

Publisher's PDF, also known as Version of record

\section{Document license:}

Taverne

\section{Please check the document version of this publication:}

- A submitted manuscript is the version of the article upon submission and before peer-review. There can be important differences between the submitted version and the official published version of record. People interested in the research are advised to contact the author for the final version of the publication, or visit the DOI to the publisher's website.

- The final author version and the galley proof are versions of the publication after peer review.

- The final published version features the final layout of the paper including the volume, issue and page numbers.

Link to publication

\footnotetext{
General rights rights.

- You may freely distribute the URL identifying the publication in the public portal. please follow below link for the End User Agreement:

www.umlib.nl/taverne-license

Take down policy

If you believe that this document breaches copyright please contact us at:

repository@maastrichtuniversity.nl

providing details and we will investigate your claim.
}

Copyright and moral rights for the publications made accessible in the public portal are retained by the authors and/or other copyright owners and it is a condition of accessing publications that users recognise and abide by the legal requirements associated with these

- Users may download and print one copy of any publication from the public portal for the purpose of private study or research.

- You may not further distribute the material or use it for any profit-making activity or commercial gain

If the publication is distributed under the terms of Article $25 \mathrm{fa}$ of the Dutch Copyright Act, indicated by the "Taverne" license above, 


\title{
Research Report
}

\section{Morphophonological influences on the comprehension of subject-verb agreement: An ERP study}

\author{
Els Severens ${ }^{a, *}$, Bernadette M. Jansma ${ }^{b}$, Robert J. Hartsuiker ${ }^{a}$ \\ ${ }^{a}$ Department of Experimental Psychology, Faculty of Psychology and Educational Sciences, Ghent University, H. Dunantlaan 2, 9000 Gent, Belgium \\ ${ }^{b}$ Maastricht University, Faculty of Psychology, Department of Cognitive Neuroscience, The Netherlands
}

\section{A R T I C L E I N F O}

Article history:

Accepted 14 May 2008

Available online 2 July 2008

Keywords:

Subject-verb agreement

Sentence comprehension

Production

Event-related potentials

\begin{abstract}
A B S T R A C T
Event-related potentials were used to study whether factors known to influence subjectverb number agreement in production exert analogous effects on sentence comprehension. Participants read Dutch sentences containing subject-verb number agreement errors while their brainwaves were measured. The determiner of the singular head noun could be ambiguous or unambiguous in number and the modifier ("local") noun could be plural or singular. Both ambiguity and number match affect error rates in production. We expected evoked potentials in response to the verb to be modulated by number ambiguity; larger effects were expected when the sentences started with an unambiguous determiner. When the local noun was singular, we observed a more negative wave elicited by the incorrect verbs compared to the correct verbs in the $350-400 \mathrm{~ms}$ time-window. This effect was largest when the head noun phrase contained no number ambiguity. When the local noun was plural the waves were more positive for incorrect verbs than for correct verbs in the 600$650 \mathrm{~ms}$ time-window. Again this effect was largest when the head noun phrase contained no number ambiguity. Most importantly, the results show that agreement computation in comprehension is influenced by the same factors as in production. We further suggest that in the sentences with a singular local noun there is a shallow analysis of the sentence, but the sentences with a plural local noun require a deeper syntactic analysis.
\end{abstract}

(c) 2008 Elsevier B.V. All rights reserved.

\section{Introduction}

When we are talking, listening, or reading we constantly have to compute agreement between the subject and the verb. This is true in many languages (one exception is Chinese), and even very young children already know how to do this (Hoekstra and Hyams, 1998; Rondal, 1978). Many studies have examined subject-verb agreement in production, typically by eliciting agreement errors (e.g., Bock and Cutting, 1992; Bock and
Eberhard, 1993; Bock and Miller, 1991; Eberhard, 1997; Hartsuiker and Barkhuysen, 2006; Vigliocco et al., 1995). The few studies that have investigated subject-verb agreement in comprehension studies suggest some similarities in findings in production and comprehension (Deevy, 2000; Nicol et al., 1997; Pearlmutter et al., 1999). It is thus possible that the mechanisms of agreement processing in production and in comprehension are the same. This paper therefore asks whether comprehension of sentences with correct and

\footnotetext{
* Corresponding author. Department of Experimental Psychology, Ghent University, Henri Dunantlaan 2, B-9000 Ghent, Belgium. Fax: +32 9 2646496.

E-mail address: els.severens@ugent.be (E. Severens).
} 
incorrect agreement is affected by similar factors that promote correct and incorrect agreement in production.

In production it is obligatory to compute number agreement to be able to generate grammatically correct sentences (with the possible exception of sentences that carry no overt number markers, as is true of the past tense forms of many English verbs). According to the currently most explicit proposal, the marking and morphing account (Bock et al., 2004; Eberhard et al., 2005), production of verb agreement requires that notional number information (singleton vs. multitude) is marked on a representation of the subject phrase, which is later integrated with lexical number specifications of all the nouns in that phrase. The result of this integration process, a number value, is then copied to the verb phrase and determines whether a singular or plural verb is produced.

However in comprehension the computation of agreement might easily be bypassed. Specifically, it is possible that in comprehension there is sometimes a shallow analysis of the sentence so that no active computation of agreement takes places. Especially in languages like Dutch and English in which the word order in sentences is relatively fixed, comprehenders can often determine the subject by its linear position in a sentence. Thus they do not have to compute if the subject and the verb agree in number to find out what the subject is. This is in line with the suggestion of Ferreira (2003) that comprehenders use a "good enough analysis" while comprehending sentences. She suggested that comprehenders use a mixture of heuristics and syntactic algorithms to understand a sentence. Because of the use of heuristics, the analysis of a sentence is not always the syntactic correct one. It is however also possible that in comprehension agreement is always calculated. In some parsing models, which are inspired by linguistic theory, agreement is an automatic byproduct of a unification process which adds incoming words and constituents to the unfolding parse tree (e.g., Vosse and Kempen, 2000). Additionally, studies using a subject-decision task (i.e., which noun in this sentence is the subject?) have shown that agreement is among the most important predictors of subjectdecision in languages like Dutch and English (e.g., Kilborn and Cooreman, 1987). Finally, studies measuring evoked potentials in comprehension have consistently found ERP-effects in response to agreement violations (e.g., Hagoort et al., 1993; Kaan 2002; Osterhout and Mobley, 1995), although we note that these effects appear to be rather vulnerable to specific aspects of the task, stimuli, and stimulus list composition.

How would the comprehension system compute subjectverb agreement? We hypothesize that the mechanisms are similar to those in production. Specifically, when the parser encounters a canonical (subject-first) sentence like "The busy street near the Gothic churches is narrow", we assume it builds up an initial parse tree consisting of a noun phrase which is composed of another noun phrase ("the busy street") and a prepositional phrase ("near the Gothic churches"). The parser would assign subjecthood to the noun phrase "the busy street near the Gothic churches", with "street" as the subject head noun. Just as in production, the root of the subject phrase would receive a number specification based on notional number of the head noun (singular in this case), and on the lexical number specifications of the nouns street (singular) and churches (plural). When the verb is is subsequently read, its number specification (singular) is then integrated with that of the subject phrase. If the numbers agree, further processing can continue. But if there is a disagreement between the two numbers, the parser might attempt to reanalyze the sentence. If this account of similar mechanisms is correct, the prediction follows that the same factors that promote agreement errors in production will affect the processing of agreement in comprehension. We now turn to such factors in production.

Production experiments have often elicited subject-verb number agreement errors, in which the subject and verb do not agree in number. In such experiments (e.g., Bock and Cutting, 1992; Bock and Miller, 1991) participants typically repeat and complete sentence fragments like "the [key/keys] to the [cabinet/cabinets]". This naturally leads to the production of a verb, which in languages like English and Dutch carries an overt marker for number for at least some combinations of person and tense. It has often been found that there were more agreement errors when the head noun ("key") was singular and the local noun ("cabinets") was plural compared to when the local noun was singular ("cabinet"). These so-called "attraction errors" (Zandvoort, 1961) have been found in several languages and with several experimental procedures (e.g., Dutch and German: Hartsuiker et al., 2003; English: Bock and Miller, 1991; French: Fayol et al., 1994; Italian: Vigliocco et al., 1995; Slovak: Badecker and Kuminiak, 2007; Slovene: Harrison, 2004; Spanish: Vigliocco et al., 1996). It is important to note that attraction is asymmetrical: attraction errors tend to occur with singular subjects, but not with plural subjects. According to the marking and morphing account, there are more agreement errors in the mismatch condition because the lexical number specification of the local noun interferes with the determination of the subject's number, but only when the local noun is plural.

Importantly, the attraction effect can be influenced by morphophonological factors (Hartsuiker et al., 2001; Hartsuiker et al., 2003; Vigliocco et al., 1995). In one of the experiments of Hartsuiker et al. (2003), participants completed Dutch sentence fragments that varied with respect to the morphophonological ambiguity of the head noun's determiners. Specifically, these sentence fragments started with either a common-gender or a neuter-gender head noun. In Dutch the common-gender determiner de is ambiguous in number, it can both be singular and plural (singular: "de straat [the street]", plural: "de straten [the streets]"). In contrast the neuter-gender determiner het is unambiguous in number, it can only be singular (singular: "het plein [the square]", plural: "de pleinen [the squares]"). In the conditions with singular head nouns and plural local nouns, participants made more agreement errors when the sentence fragments started with a common-gender (ambiguous) determiner than when they started with a neuter-gender (unambiguous) determiner. The finding that morphophonological factors influence the number of agreement errors can also be explained by the marking and morphing account. Since morphing uses morphophonological information to assign number to a noun, it is possible that the value "plural" is sometimes spuriously assigned in the case of ambiguous determiners. Therefore, there is more interference when the number of the verb has to be calculated, resulting in 


\section{A. common gender noun match}

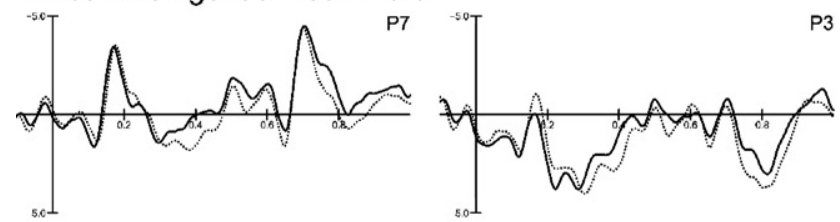

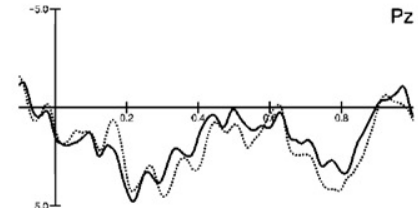

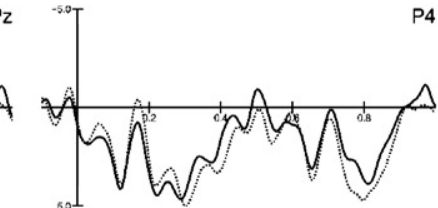

$\Delta 4$

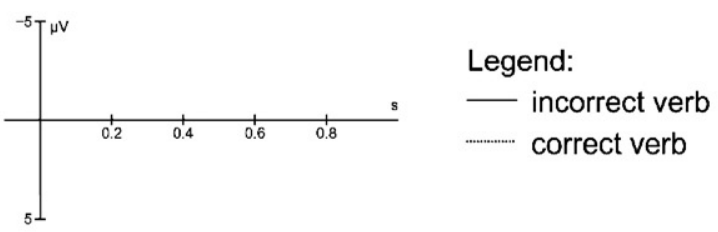

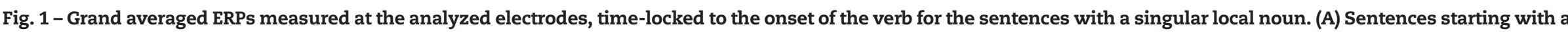

common-gender head noun. (B) Sentences starting with a neuter-gender head noun.

B. neuter gender noun match
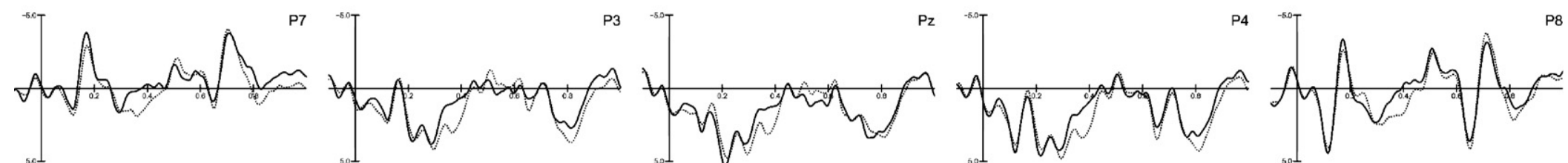
A. common gender noun mismatch
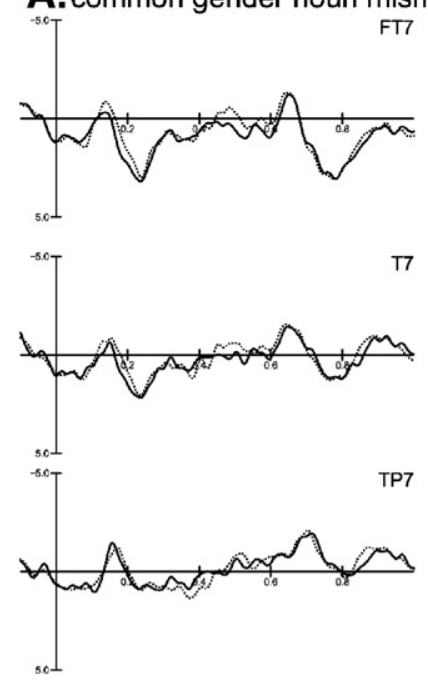
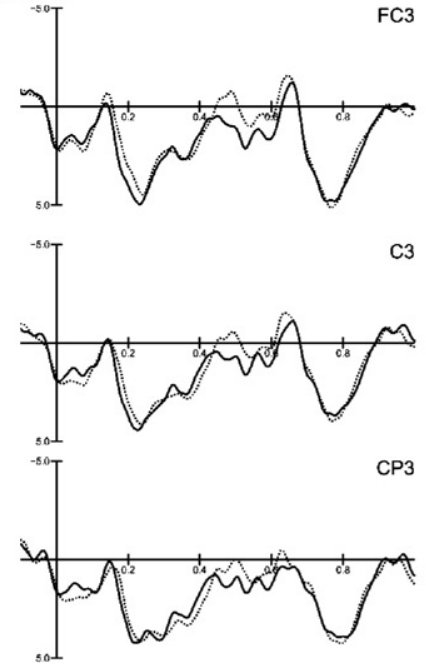

FC3

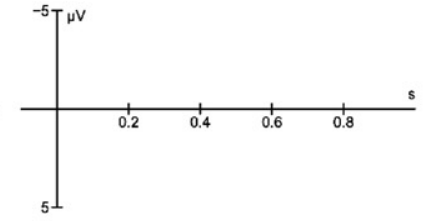

Legend:

- incorrect verb

........... correct verb
B. neuter gender noun mismatch
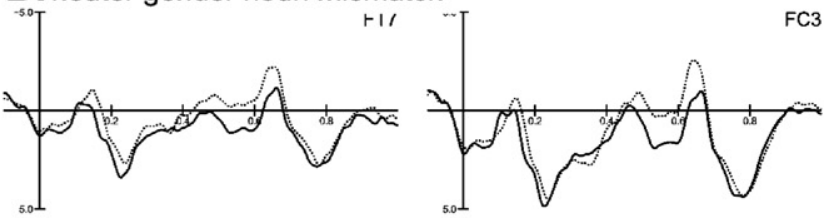

T7
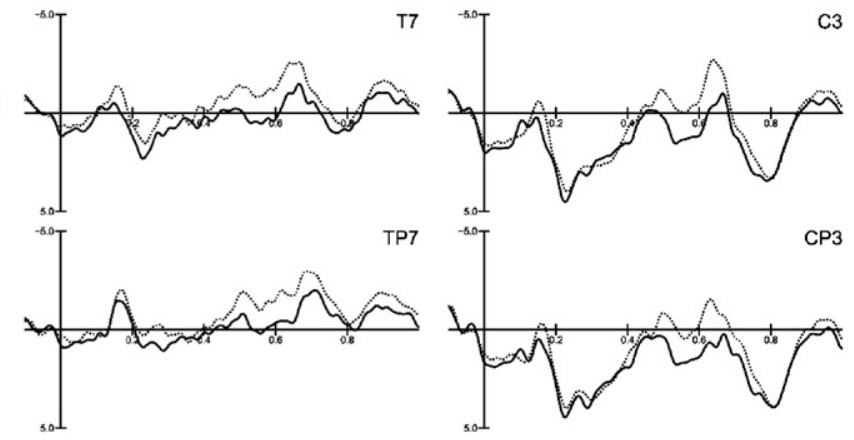

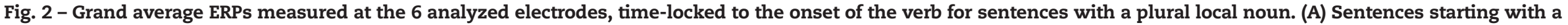
common-gender head noun (B) Sentences starting with a neuter-gender head noun. 
a larger number of subject-verb agreement errors in the common-gender determiner condition.

In support of a similar-mechanisms account, an analogue of the attraction effect has been found in several comprehension studies. Pearlmutter et al. (1999) presented sentences like "The key to the [cabinet/cabinets] [was/were] rusty from many years of disuse". In both self-paced reading and in eye-tracking they found that reading times were longer when either the local noun (cabinets) or the verb was plural (also see Nicol et al., 1997). Kaan (2002) found a similar effect in an ERP study. She observed a larger P600 (i.e., difference wave between correct and incorrect condition) in the singular head noun/singular local noun condition compared to the singular head noun/ plural local noun condition. To our knowledge there are no studies that investigated morphophonological influences on the comprehension of subject-verb agreement, therefore the present study aims to examine this.

To test if there are comparable morphophonological influences in comprehension we used similar sentences to the ones of Hartsuiker et al. (2003). We restricted the materials to sentences with singular nouns, because in conditions with plural nouns it is not possible to manipulate ambiguity (all plural nouns require the determiner de). Also note that in the study of Hartsuiker et al. as well in other studies (e.g., Bock and Miller, 1991), there was no attraction effect with plural subjects. In the present study ERPs were used since this allows for a good online measurement of cognitive processes.

One ERP component of interest is the P600, which is a positive going wave starting around $500 \mathrm{~ms}$ after stimulus onset with a centro-parietal distribution. Various kinds of syntactic violations have been shown to influence the amplitude of the P600. Importantly, studies have observed a $\mathrm{P} 600$ in response to subject-verb agreement violations (for an overview see Vos et al., 2001). It is important to note, however, that several studies have observed a negativity with such errors, or a complex pattern in which the $\mathrm{P} 600$ is preceded by a negativity. Most often this negativity has a left anterior distribution (LAN: e.g., Chen et al., 2007; Munte et al., 1997; Osterhout and Mobley, 1995) but also a more central distribution similar to the $\mathrm{N} 400$ has been reported (Coulson et al., 1998b; Gunter, and Friederici, 1999).

There is an ongoing debate about the functional interpretation of the $\mathrm{P} 600$-effect. It has been claimed to index syntactic processing (e.g., Hagoort et al., 1993; Osterhout, and Holcomb, 1995), syntactic repair or reanalysis (Friederici et al., 1996; Munte et al., 1997), syntactic integration difficulty (Kaan et al., 2000), more salient violations indexed by the proportion of violations in the sentences (Coulson et al., 1998a), or monitoring for processing errors (Kolk et al., 2003; Van Herten et al., 2006; Vissers et al., 2006). Recently the P600 has been suggested to reflect ongoing combinatory analysis (Kuperberg, 2007). With respect to violations of number agreement, it seems fair to say that all these proposals are consistent with the P600 being modulated by the degree of number-conflict: the more conflict, the larger the demands on the syntactic processor.

We expect to find a larger $\mathrm{P} 600$ when the verb does not agree with the subject; this is the basic P600 effect. More importantly, we expect to find a larger effect when the sentence starts with the neuter-gender determiner (unambig- uous), because in this case the lexical information of the head noun's determiner indicates that the head noun is singular. Thus when a plural verb is encountered the conflict is larger compared to when there was a common-gender determiner (ambiguous) and a larger effect is expected. Both the noun number match (singular local noun) and the noun number mismatch (plural local noun) conditions are hypothesized to elicit a P600 effect, however this effect is expected to be larger in the noun number match condition since the conflict is the largest here. In the noun number match condition the number of all the nouns is singular.

\section{Results}

\subsection{Comprehension task}

The mean error rate of the comprehension questions was $6.05 \%$, indicating that the participants read and processed the sentences with sufficient attention.

\subsection{Event-related potentials}

Grand average event-related potentials time-locked to the onset of the verb for the singular local noun (noun number match) conditions are shown in Fig. 1 and for the plural local noun (noun number mismatch) conditions in Fig. 2.

All conditions elicited an N1-P2 complex, as is typical for visual stimuli. Visual inspections suggested that in the noun number match condition there was a negativity around $400 \mathrm{~ms}$ in both gender conditions, with a more negative wave for the incorrect verbs compared to the correct verbs. Based on the central-parietal distribution of this effect we believe that this effect is a N400. In the noun number mismatch condition there seemed to be a P600 in both gender conditions, with a more positive wave for the incorrect verb than for the correct verb. Based on visual inspection of the data two time-windows were analyzed: $350-400 \mathrm{~ms}$ in the noun number match condition and 600-650 ms noun number mismatch condition. Additionally, based on visual inspection of the effect topography we compared the mean amplitudes of conditions in the 350-400 ms time-window separately for P7, $\mathrm{P} 3, \mathrm{Pz}, \mathrm{P} 4$, and $\mathrm{P} 8$, and the mean amplitudes of conditions in the 600-650 ms time-window separately for FT7, FC3, T7, C3, TP7 and CP3.

\subsubsection{Noun number match conditions}

The omnibus ANOVA in the time-window 350-400 ms had the factors gender of head noun (common, neuter), grammaticality (correct, incorrect) and electrodes (31 electrodes). The analysis showed significant main effects of grammaticality $(F(1,31)=16.27, p<0.01)$ and of gender of head noun $(F(1,31)=3.17, p<0.05)$ and a significant interaction of grammaticality $\times$ electrodes $(F(30,930)=3.49, p<0.01)$. A more specific analysis of the parietal electrodes showed a significant main effect of grammaticality $(F(1,31)=13.93, p<0.01)$ and a marginally significant interaction between grammaticality $\times$ gender of head noun $(F(1,31)=3.78, p=0.06)$. As is visible in the ERP-waves and in Fig. 3, the incorrect verbs elicited a more negative going wave than the correct verbs and this effect was largest when 


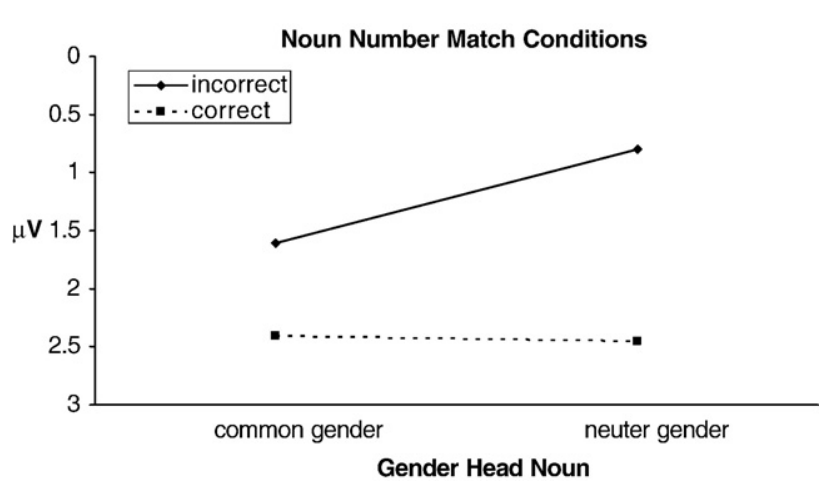

Fig. 3 - Mean amplitudes for the time-window 350 till $400 \mathrm{~ms}$ are shown for both the correct and the incorrect verbs in the mismatch sentences for the neuter-gender and the common-gender head noun conditions.

the sentence started with a neuter-gender noun (unambiguous). The ANOVA on topographical similarities showed no significant interaction of gender and electrodes $(F(30,930)$ $=1.10, p=0.36)$, suggesting that the topographical distribution of the effect in the common-gender and the neuter-gender condition was the same.

\subsubsection{Noun number mismatch condition}

The omnibus ANOVA in the time-window 600-650 ms, revealed a significant main effect of grammaticality ( $F$ $(1,31)=7.39, p<0.05)$. There was a significant interaction of grammaticality $\times$ electrodes $(F(30,930)=3.08, p<0.05)$. A more specific analysis at left central/frontal sites showed a significant main effect of grammaticality $(F(1,31)=11.03, p<0.01)$ and a significant interaction of grammaticality $\times$ gender of head noun $(F(1,31)=4.42, p<0.05)$ and of grammaticality $\times$ electrode $(F(5,155)=4.47, p<0.01)$. The grammaticality $\times$ gender of head noun interaction is visualized in Fig. 4: the waves elicited by the incorrect verbs were more positive than those elicited by the correct verbs; this effect was larger when the gender was neuter (unambiguous) than when it was common (ambiguous). Additionally the effect seemed to be longer lasting in the neuter-gender condition, we believe this is caused by the fact that there are more errors detected in the neuter-gender condition. This caused an effect that is larger but also longer. The ANOVA on topographical similarities between the effect found in the common-gender and neuter-gender condition did not show a significant interaction of gender and electrodes $(F(30,930)=1.83, p=0.12)$. The non-significant interaction suggests that there was no topographical difference between the effect found in the common-gender and the neuter-gender condition.

\section{Discussion}

In the current study we investigated whether subject-verb number agreement computation in comprehension is influenced by the same factors that have been found to influence subject-verb agreement in behavioral production studies (Hartsuiker et al., 2003). As in the behavioral experiment of
Hartsuiker et al., we presented sentences with singular head nouns and singular or plural local nouns and manipulated the gender of the head noun, so that the corresponding determiner was or was not ambiguous for number. We presented both correct (singular) and incorrect (plural) verbs and measured ERP, time-locked to verb onset. In the noun number mismatch condition we found a P600 for incorrect verbs compared to correct verbs. This $\mathrm{P} 600$ effect was larger in the neuter-gender (unambiguous) determiner condition compared to the common-gender (ambiguous) determiner condition. Additionally, this effect appeared to have a similar topographical distribution in both gender conditions, suggesting that it is caused by the same neural generator. In the noun number match condition we found a N400 for incorrect verbs compared to correct verbs, which was larger when the sentence started with a neuter-gender (unambiguous) determiner than when it started with a common-gender (ambiguous) determiner. Again the topographical distribution in both gender conditions was similar. First, we will discuss the modulation of the effects by ambiguity of the head noun's determiner. Second, we discuss a possible reason for the appearance of a N400 in the noun number match condition and a P600 for the noun number mismatch condition.

\subsection{Influence of number ambiguity}

In the production studies it has been found that the number of agreement errors is modulated by number ambiguity of the head noun's determiner. There were more agreement errors when the sentence started with a common-gender determiner compared to when it started with a neuter-gender determiner (Hartsuiker et al., 2003). One explanation for this finding can be found in the marking and morphing account in which morphophonological information is used to assign number. Because the common-gender determiner is ambiguous in number, a plural number specification can be spuriously assigned, resulting in more agreement errors. If in comprehension morphophonological information is also used to compute number agreement, this would result in a larger conflict in the neuter-gender condition when the incorrect plural verb is encountered. In this condition the determiner's gender and the head noun both point to singular. In contrast, when the sentence start with a common-gender determiner

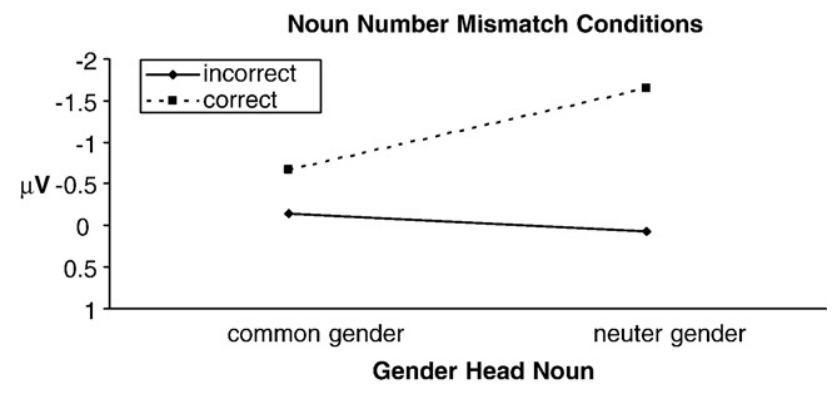

Fig. 4-Mean amplitudes for the time-window 600 till $650 \mathrm{~ms}$ are shown of both the correct and the incorrect verbs in the mismatch sentences for the neuter-gender and the common-gender head noun conditions. 
this will also point to plural, reducing the conflict when the incorrect plural verb is encountered. Therefore we expected to find a larger P600 effect when the sentences started with a neuter-gender determiner and this expectation was confirmed. The computation of number agreement in comprehension is influenced by the same factors as in production, suggesting that the processes might be similar.

The modulation of the effects by ambiguity can also be explained by a biased monitoring account. In the production literature it is often suggested that there is an internal selfmonitor that inspects speech for errors and that this monitor relies on the comprehension system (Levelt et al., 1999). Since the monitor uses the comprehension system Hartsuiker (2006) suggested that when a bias found in production is explained by a biased internal self-monitor, a similar bias has to be present in comprehension. Indeed, the effect of number ambiguity of the head noun's determiner in production can be explained by a monitor that finds it harder to detect errors when a sentence starts with a common-gender determiner (Hartsuiker et al., 2003). In other words, more subject-verb agreement errors are detected and covertly corrected when the sentences started with a neuter-gender determiner which in turn results in fewer overt subject-verb agreement errors. If there is a similar bias in comprehension it should also be easier for the comprehension system to detect subject-verb agreement errors when the sentence started with a neutergender determiner, and so larger effects can be expected in this condition. Note that this explanation only applies to the mismatch conditions; in production, the number of subjectverb agreement errors in the match conditions are at floor, regardless of number ambiguity (Hartsuiker et al., 2003).

\subsection{N400 us. $p 600$}

A striking finding in the present study is that there was a P600 in the noun number mismatch conditions and a N400 in the noun number match conditions. The $\mathrm{P} 600$ found in the noun number mismatch condition was as expected, because the P600 is elicited by syntactic violations like an incorrect verb (e.g., Hagoort et al., 1993; Osterhout and Holcomb, 1995). The $\mathrm{N} 400$ found in the noun number match conditions was not expected, but it is important to note that previous studies sometimes also found negativities to syntactic violations. These include a left anterior negativity (LAN) (Chen et al., 2007; Munte et al., 1997; Osterhout and Mobley, 1995), but more importantly, also a more centrally distributed component (N400) as was the case in our data (Coulson et al., 1998b; Gunter and Friederici, 1999).

To account for this data pattern, we take our cue from several recent studies that observed the opposite pattern from our findings. These studies reported a P600 instead of a N400 in semantic verb-argument violations (Hoeks et al., 2004; Kim and Osterhout, 2005; Kolk et al., 2003; Van Herten et al., 2005; Kuperberg et al., 2003; see Kuperberg, 2007 for overview). These studies presented sentences like "Every morning at breakfast the eggs would eat..." Grammatically, this sentence is correct, but the verb eat does not fit semantically when "eggs" has the thematic role of agent. To account for these findings, Kuperberg (2007) argued that there are two processing streams in comprehension. A first, syntactically shallow, processing stream is reflected by the N400 and is based on semantic memory. This process computes semantic features and relationships between words. Because "eggs" and "eat" are semantically associated, this stream would tend to accept the "eggs-eat" sentence. The second processing stream is a combinatory stream which uses multiple constraints, like morphosyntactic and semantic-thematic constraints, to build up sentence meaning. Because this stream will detect the violation of selection restrictions in the example above, it will tend to reject that sentence. Kuperberg suggested that these processes work at least partially in parallel. When there is conflict between these two streams, continued combinatory analysis will take place which is reflected by the P600. But when there is no conflict between the streams (i.e., a blatant violation like "the telephone will eat") there will be an N400.

We suggest that the difference in components presently elicited in the noun number match and noun number mismatch conditions likewise reflects a difference in the amount of syntactic processing when the parser attempts to integrate the incorrect verb in the unfolding sentence. All sentences presented to our participants had the identical syntactic structure, in which the first noun was always the subject head noun. A shallow processing stream might thus build up the expectation that the verb's number will correspond to that of the first noun. This expectation will even be stronger when the determiner of the first noun is unambiguously singular. In the noun number match conditions, this expectation can be maintained when the second noun is read, because that noun's number is consistent with the number expected of the verb. When subsequently an incorrect (plural) verb is read, there is a violation of this expectation, which cannot be repaired by further syntactic processing: even if the second noun were the subject head, there would still be disagreement between noun and verb.

In contrast, in the noun number mismatch conditions, there is a strong conflict between two potential analyses, namely the analysis suggested by the shallow processing stream on which the first noun is the subject head, and an analysis suggested by noun and verb number, on which the second noun is the subject head. To resolve this conflict, further syntactic processing is necessary and this extra work is reflected in the $\mathrm{P} 600$ component. In summary, on this account the $\mathrm{P} 600$ reflects ongoing syntactic processing when a shallow and a combinatory processing stream conflict, whereas the $\mathrm{N} 400$ is a response to a blatant violation of the expected word, which cannot be repaired by further analysis.

One objection to this account might be that Kaan (2002) found a P600 instead of a N400 in the match condition. However, in that experiment the participants made grammaticality judgments. It is very much conceivable that this explicit task had important consequences for the participants' parsing strategies: in particular, the grammaticality judgments may have forced further syntactic processing even in the noun match conditions. There is indeed evidence for such task-effects: some studies observed a P600 in an explicit plausibility judgment task, but no $\mathrm{P} 600$ in a free reading task with the same stimuli (Geyer et al., 2006; Kolk et al., 2003).

Perhaps a more wounding objection is that even in studies without an explicit task, verb agreement errors in simpler constructions (e.g., "*the newly elected officials hopes..."; 
Osterhout and Mobley, 1995; Experiment 3) have been shown to elicit a P600, not an N400. It is possible, however, that the much greater diversity in sentence structure in these studies has promoted a deeper syntactic analysis than in our experiment. Indeed, one consequence of such diversity is that the combinatory processing stream may attempt several analyses, which could promote conflict. For example, in Osterhout and Mobley's sentence above, this processing stream may consider an analysis on which "hopes" is a noun in a genitive construction (with an apostrophe missing) rather than a verb ("the hopes of the newly elected officials"). Similarly, in Dutch sentences like "*het verwende kind gooien het speelgoed op de grond ("*the spoilt child throw[plural] the toy on the ground"; Hagoort et al., 1993), the parser may attempt the analysis by which "the spoilt child" is the object, rather than the subject of the verb, a marked but grammatically correct possibility in Dutch, as in "het verwende kind gooien we in het water (the spoilt child [object] throw we [subject] in the water").

Although more work is surely needed to understand agreement processing in sentence comprehension, our data suggest that if a strong expectation can be build there is a shallow analysis of the sentence and syntactic analysis is not necessary. Thus in comprehension there are circumstances in which there is no need to compute subject-verb agreement. However, when no strong expectation can be build there is need for a deeper syntactic analysis of the sentences.

\subsection{Conclusions}

Most importantly, the current results support the suggestion that similar mechanisms account for the computation of subject-verb number agreement in production and in comprehension. The comprehension of subject-verb number agreement is likewise influenced by morphophonological factors as production is. Additionally, the current results suggest that there are at least two ways in which the parser can deal with the kind of sentences presented under the specific circumstances of our experiment, depending on whether the local noun is singular or plural. We suggest that when the local noun is singular a strong expectation is built and there is only a shallow analysis of the sentence. In contrast when the local noun is plural, there is a deeper syntactic analysis.

\section{Experimental procedures}

\subsection{Participants}

Thirty-six Ghent University students, native speakers of Dutch, volunteered in exchange for money to participate in the experiment. Four participants were excluded from further analysis because of too many artifacts in the ERP signal. Participants' ages ranged between 19 and 25 (mean=21.39), 21 of the participants were female. Handedness was assessed via a questionnaire (Van Strien, 1992), with possible scores ranging from -10 (extremely left-handed) to 10 (extremely right-handed). Participants were all right-handed as shown by their average score of $9.55(\mathrm{SD}=1.36)$. All participants reported to have normal or corrected-to-normal vision and no history of neurological and psychiatric disorders.

All the participants in the experiment were informed and signed written consent.

\subsection{Materials}

We constructed 160 sets of Dutch sentences with the structure exemplified in 1 and 2. Each set contained eight versions of each sentence, resulting from the crossing of three factors: gender of the head noun (neuter or common-gender, latter is ambiguous), number of the local noun (singular or plural), and grammaticality (correct or incorrect). All the local nouns required the determiner "de". An example of these sentences is given in 1 and 2 .

1. De straat bij de kerk/kerken is/*zijn mooi [Translation: The street(common-gender) near the church/churches is/*are beautiful]

2. Het plein bij de kerk/kerken is/*zijn mooi [Translation: The square $_{\text {(neuter-gender) }}$ near the church/churches is/*are beautiful]

Four lists were constructed; each list contained 160 sentences starting with a common-gender head noun (ambiguous) and 160 sentences starting with a neuter-gender head noun (unambiguous). For both the sentences starting with a common-gender and neuter-gender head noun, half had a singular local noun and half had a singular verb, resulting in 40 sentences of each type. This resulted in lists in which half of the sentences were incorrect. Within each list, one version of each sentence appeared in the common-gender head noun (ambiguous) condition and one version appeared in the neuter-gender head noun (unambiguous) condition. Across the four lists, the ambiguous and unambiguous sentence occurred once in the four combinations of number match and grammaticality.

All lists contained 320 filler sentences, with the same syntactic structure as the experimental sentences. The filler items started with a plural subject so that across all experimental and filler trials a plural verb would be correct in $50 \%$ of trials. Half of the filler items contained a subject-verb agreement error. The resulting four 640-sentence lists were randomized separately for each participant.

In addition, participants occasionally answered yes-no questions on sentence content appearing at random between the target sentences via a button press (on average 1 question each 20 sentences, with a total of 32) to control participants attention during reading. All the questions were related to the adjective; a question for the example sentence 1 could be: "Is the street beautiful?".

\subsection{Procedure}

After electrode placement participants were seated in an electrically shielded room in front of a computer screen. Participants were told to attentively read the sentences and not to move or blink while the sentences were presented on the screen. First the participants performed a practice session; the experimental session only started when this practice 
session was performed correctly. Each trial started with a fixation cross in the center of the screen for $1500 \mathrm{~ms}$ and a blank screen for $500 \mathrm{~ms}$, followed by a word-by-word presentation of the sentences. Each word was presented for $325 \mathrm{~ms}$ and followed by a blank screen for $200 \mathrm{~ms}$, after the last word there was a blank screen for $500 \mathrm{~ms}$. The questions were presented as a whole, and disappeared if the participant answered the question with a button press. One block took approximately $9 \mathrm{~min}$ and the entire experiment, including electrode placement and removal, took about $2.5 \mathrm{~h}$.

\subsection{EEG recording and analysis}

EEG was recorded with 31 scalp electrodes, placed according to the International 10-20 setting, all referenced to the mean of all scalp electrodes ${ }^{1}$. EOG was measured bipolarly; vertical eye movements and blinks were measured with two electrodes placed above and below the left eye, two electrodes placed on the left and the right outer canthus were used to measure horizontal eye movements. Impedances of all the electrodes were kept below $3 \mathrm{~K} \Omega$. The signal of all electrodes was rereferenced off-line to the average signal of the electrodes placed on the left and the right mastoid. The EEG was digitized at $512 \mathrm{~Hz}$. The continuous EEG was filtered off-line with a band pass filter of $0.01-30 \mathrm{~Hz}$.

EEG data were analyzed using EEProbe 3.1 (ANT, Inc., Enschede, The Netherlands) running on Red Hat Linux 7. ERPs were time-locked to the onset of the critical verb and epochs were generated with a time-window from -100 to $1000 \mathrm{~ms}$ around the onset of the verb. Epochs containing artifacts, such as blinks, were rejected from further analysis; the overall rejection rate of the analyzed participants was $11.55 \%$, there was no difference in rejection rate between the conditions. Based on visual analysis of the data, the mean area amplitudes were subjected to two separate repeated measures ANOVAs with the Factors Gender of head noun (common/neuter), Grammaticality (correct/ incorrect) and Electrodes (31), one ANOVA for the singular local noun condition and one for the plural local noun condition.

Additionally, to show that the effects found in the neutergender condition and the common-gender condition are the same component, we tested if the effects found in these conditions differed in topographical distribution. In order to do this the difference of the incorrect and the correct condition were calculated in the $350-400 \mathrm{~ms}$ and the 600-650ms timewindow for both the neuter-gender and common-gender conditions. Following McCarthy and Wood (1985), the data was first normalized to make sure that the overall amplitude difference could not influence the topographical distribution.

\footnotetext{
${ }^{1}$ The hardware of the amplifier is programmed in a way that we are obligated to take the averaged signal of all electrodes as a reference. Dien (1998) suggests that to be able to compare results of different studies similar reference sites should be used. Since most studies use the average signal of the right and the left mastoid as a reference, we off-line re-referenced to the average signal of these two electrodes.
}

Two separate repeated measures ANOVAs were carried out with gender (common/neuter) and electrodes (31) as factors. If there was no significant interaction between gender and electrodes it was assumed that the topographic distribution was the same for the neuter-gender and the common-gender condition. When there was more than one degree of freedom in the numerator the Greenhouse-Geisser correction was applied, the corrected $p$-values were reported. The degrees of freedom are reported uncorrected.

\section{Acknowledgments}

This research was supported by a grant from the Ghent University special research fund (BOF 011/098/04) and (BOF 07377/02). This research was also supported by a special scholarship from the Fund for Scientific Research (Flanders, Belgium) to Els Severens. We would like to thank Eva Van Assche for helping to prepare the subjects.

\section{REFERENCES}

Badecker, W., Kumimak, F., 2007. Morphology, agreement and working memory retrieval in sentence production: evidence from gender and case in Slovak. J. Mem. Lang. 56 (1), 65-85.

Bock, K., Cutting, J.C., 1992. Regulating mental energyperformance units in language production. J. Mem. Lang. 31 (1), 99-127.

Bock, K., Eberhard, K.M., 1993. Meaning, sound and syntax in english number agreement. Lang. Cogn. Processes 8 (1), 57-99.

Bock, K., Eberhard, K.M., Cutting, J.C., 2004. Producing number agreement: how pronouns equal verbs. J. Mem. Lang. 51 (2), 251-278.

Bock, K., Miller, C.A., 1991. Broken agreement. Cogn. Psychol. 23 (1), 45-93.

Chen, L., Shu, H., Liu, Y., Zhao, J., Li, P., 2007. ERP signatures of subject-verb agreement in L2 learning. Bilingualism: Lang. and Cogn. 10 (2), 161-174.

Coulson, S., King, J.W., Kutas, M., 1998a. ERPs and domain specificity: beating a straw horse. Lang. Cogn. Processes 13 (6), 653-672.

Coulson, S., King, J.W., Kutas, M., 1998b. Expect the unexpected: event-related brain response to morphosyntactic violations. Lang. Cogn. Processes 13 (1), 21-58.

Deevy, P.L., 2000. Agreement checking in comprehension: evidence from relative clauses. J. Psycholinguist. Res. 29 (1), 69-79.

Dien, J., 1998. Issues in the application of the average reference: review, critiques, and recommendations. Behav. Res. Meth. Instrum. Comput. 30 (1), 34-43.

Eberhard, K.M., 1997. The marked effect of number on subject-verb agreement. J. Mem. Lang. 36 (2), 147-164.

Eberhard, K.M., Cutting, J.C., Bock, K., 2005. Making syntax of sense: number agreement in sentence production. Psych. Rev. $112(3), 531-559$.

Fayol, M., Largy, P., Lemaire, P., 1994. Cognitive overload and orthographic errors - when cognitive overload enhances subject verb agreement errors - a study in French written language. Q. J. Exp. Psychol., A Human Exp. Psychol. 47 (2), 437-464.

Ferreira, F., 2003. The misinterpretation of noncanonical sentences. Cogn. Psychol. 47 (2), 164-203.

Friederici, A.D., Hahne, A., Mecklinger, A., 1996. Temporal structure of syntactic parsing: early and late event-related 
brain potential effects. J. Exper. Psychol., Learn., Mem., Cogn. 22 (5), 1219-1248.

Geyer, A., Holcomb, P., Kuperberg, G., Pearlmutter, N.J., 2006. Plausibility and sentence comprehension. An ERP study. cognitive neuroscience suppl Abstract.

Gunter, T.C., Friederici, A.D., 1999. Concerning the automaticity of syntactic processing. Psychophysiology 36 (1), 126-137.

Hagoort, P., Brown, C., Groothusen, J., 1993. The syntactic positive shift (SPS) as an ERP measure of syntactic processing. Lang. Cogn. Processes 8 (4), 439-483.

Harrison, A.J., 2004. Three way attraction effects in Slovene. Proceedings of the Second Camling Postgraduate Conference on Language Research. Cambridge: University of Cambridge.

Hartsuiker, R.J., 2006. Are speech error patterns affected by a monitoring bias? Lang. Cogn. Processes 21, 856-891.

Hartsuiker, R.J., Anton-Mendez, I., van Zee, M., 2001. Object attraction in subject-verb agreement construction. J. Mem. Lang. 45 (4), 546-572.

Hartsuiker, R.J., Barkhuysen, P.N., 2006. Language production and working memory: the case of subject-verb agreement. Lang. Cogn. Processes 21 (1-3), 181-204.

Hartsuiker, R.J., Schriefers, H.J., Bock, K., Kikstra, G.M., 2003. Morphophonological influences on the construction of subject-verb agreement. Mem. \& Cog. 31 (8), 1316-1326.

Hoeks, J.C.J., Stowe, L.A., Doedens, G., 2004. Seeing words in context: the interaction of lexical and sentence level information during reading. Cogn. Brain Res. 19, 59-73.

Hoekstra, T., Hyams, N., 1998. Aspects of root infinitives. Lingua 106 (1-4), 81-112.

Kaan, E., 2002. Investigating the effects of distance and number interference in processing subject-verb dependencies: an ERP study. J. Psycholinguist. Res. 31 (2), 165-193.

Kaan, E., Harris, A., Gibson, E., Holcomb, P., 2000. The P600 as an index of syntactic integration difficulty. Lang. Cogn. Processes 15 (2), 159-201.

Kilborn, K., Cooreman, A., 1987. Sentence interpretation strategies in adult Dutch English bilinguals. Appl. Psycholinguist. 8 (4), 415-431.

Kim, A., Osterhout, L., 2005. The independence of combinatory semantic processing: evidence from event-related potentials. J. Mem. Lang. 52, 205-225.

Kolk, H.H.J., Chwilla, D.J., van Herten, M., Oor, P.J.W., 2003. Structure and limited capacity in verbal working memory: a study with event-related potentials. Brain Lang. 85 (1), 1-36.

Kuperberg, G., 2007. Neural mechanisms of language comprehension: challenges to syntax. Brain Res. 1146, 23-49.

Kuperberg, G.R., Sitnikova, T., Caplan, D., Holcomb, P.J., 2003. Electrophysiological distinctions in processing conceptual relationships within simple sentences. Cogn. Brain Res. 17, 117-129.

Levelt, W.J.M., Roelofs, A., Meyer, A.S., 1999. A theory of lexical access in speech production. Behav. Brain Sci. 22 (1), 1-75.
McCarthy, G., Wood, C.C., 1985. Scalp distributions of event-related potentials: an ambiguity associated with analysis of variance models. Electroencephalogr. Clin. Neurophysiol. 62, 203-208.

Munte, T.F., Matzke, M., Johannes, S., 1997. Brain activity associated with syntactic incongruencies in words and pseudo-words. J. Cogn. Neurosci. 9 (3), 318-329.

Nicol, J.L., Forster, K.I., Veres, C., 1997. Subject-verb agreement processes in comprehension. J. Mem. Lang. 36 (4), 569-587.

Osterhout, L., Holcomb, P.J., 1995. Event-related brain potentials elicited by syntactic anomaly. In: Ruga, M.D., Coles, M.G.H. (Eds.), Electrophysiology of Mind: Event-related Brain Potentials and Cognition. pp. 171-215 Oxford University Press, New York.

Osterhout, L., Mobley, L.A., 1995. Event-related brain potentials elicited by failure to agree. J. Mem. Lang. 34 (6), 739-773.

Pearlmutter, N.J., Garnsey, S.M., Bock, K., 1999. Agreement processes in sentence comprehension. J. Mem. Lang. 41 (3), 427-456.

Rondal, J.A., 1978. Patterns of correlations for various language measures in mother-child interactions for normal and downs-syndrome children. Lang. Speech 21 (JUL-), 242-252.

van Herten, M., Kolk, H.H., Chwilla, D.J., 2005. An ERP study of P600 effects elicited by semantic anomalies. Brain Res. Cogn. Brain Res. 22, 241-255.

van Herten, M., Chwilla, D.J., Kolk, H.H.J., 2006. When heuristics clash with parsing routines: ERP evidence for conflict monitoring in sentence perception. J. Cogn. Neurosci. 18 (7), 1181-1197.

Van Strien, J.W., 1992. Classificatie van links- en rechtshandige proefpersonen (Classification of left- and right-handed subjects). Ned. Tijdschr. Psychol. 47, 88-92.

Vigliocco, G., Butterworth, B., Garrett, M.F., 1996. Subject-verb agreement in Spanish and English: differences in the role of conceptual constraints. Cognition 61 (3), 261-298.

Vigliocco, G., Butterworth, B., Semenza, C., 1995. Constructing subject verb agreement in speech-the role of semantic and morphological factors. J. Mem. Lang. 34 (2), 186-215.

Vissers, C., Chwilla, D.J., Kolk, H.H.J., 2006. Monitoring in language perception: the effect of misspellings of words in highly constrained sentences. Brain Res. 1106, 150-163.

Vos, S.H., Gunter, T.C., Kolk, H.H.J., Mulder, G., 2001. Working memory constraints on syntactic processing: an electrophysiological investigation. Psychophysiology 38 (1), 41-63.

Vosse, T., Kempen, G., 2000. Syntactic structure assembly in human parsing: a computational model based on competitive inhibition and a lexicalist grammar. Cognition 75 (2), 105-143.

Zandvoort, R., 1961. Varia syntactica. Language and Society: Essays presented to Arthur M. Jensen on his 70th Birthday. Berlingske Bogtrykkeri, Copenhagen. 